\title{
Maïté Boullosa-Joly, Magali Demanget et David Dumoulin Kervran (coord.), Tourisme patrimonial et sociétés locales
}

Dossier des Cahiers des Amériques latines, $n^{\circ}$ 65, 3/2010, Iheal, 2010, 223 pages

\section{Michel Raspaud}

\section{OpenEdition}

\section{Journals}

Édition électronique

URL : http://journals.openedition.org/tourisme/524

DOI : $10.4000 /$ tourisme.524

ISSN : 2492-7503

\section{Éditeur}

Éditions touristiques européennes

\section{Édition imprimée}

Date de publication : 1 juin 2011

Pagination : 91-94

ISSN : 2109-5671

\section{Référence électronique}

Michel Raspaud, « Maïté Boullosa-Joly, Magali Demanget et David Dumoulin Kervran (coord.)

Tourisme patrimonial et sociétés locales », Mondes du Tourisme [En ligne], 3 | 2011, mis en ligne le 30 septembre 2015, consulté le 22 septembre 2020. URL : http://journals.openedition.org/tourisme/524 DOI : https://doi.org/10.4000/tourisme.524

Ce document a été généré automatiquement le 22 septembre 2020

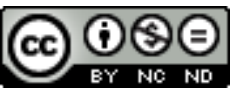

Mondes du tourisme est mis à disposition selon les termes de la licence Creative Commons Attribution - Pas d'Utilisation Commerciale - Pas de Modification 4.0 International. 


\section{Maïté Boullosa-Joly, Magali Demanget et David Dumoulin Kervran (coord.), Tourisme patrimonial et sociétés locales}

Dossier des Cahiers des Amériques latines, n 65, 3/2010, Iheal, 2010, 223 pages

\section{Michel Raspaud}

\section{RÉFÉRENCE}

Maïté Boullosa-Joly, Magali Demanget et David Dumoulin Kervran (coord.), Tourisme patrimonial et sociétés locales, Dossier des Cahiers des Amériques latines, n 65, 3/2010, Iheal, 2010.

1 Ce dossier, coordonné par Maïté Boullosa-Joly, Magali Demanget et David Dumoulin Kervran, est issu d'une table ronde ayant eu pour thème "le tourisme patrimonial, la culture comme ressource sur un marché mondial"; il se compose de six articles (pp. 17-120). L'introduction, rédigée par deux des coordonnateurs (Magali Demanget et David Dumoulin Kervran), est suivie de cinq études de cas. Évidemment, il ne traite pas de l'ensemble de cette très vaste région, mais seulement de cinq points d'ancrage : Mexique, Costa Rica, Panama, Brésil et Argentine.

Dans l'article d'introduction ("Étudier le tourisme: vers de nouveaux horizons"), les auteurs soulignent que les membres des sociétés locales mobilisent la culture comme une ressource identitaire et politique, avant même sa fonction économique. Cette dernière se voit ensuite fructifier et avoir des répercussions sociales positives. Ils remarquent également que la littérature concernant les études socio-anthropologiques 
du tourisme en Amérique latine est très mince, cet aspect ayant été laissé en friche. Ce numéro vient donc combler un vide.

3 Il s'agit de comprendre, à travers les différents articles, "la manière dont les populations patrimonialisent leur culture pour avoir accès au marché touristique". L'idée reprise ici, aujourd'hui défendue par un certain nombre de chercheurs, est de refuser "la dichotomie culture pour soi/culture pour le touriste"; les exemples développés par la suite montrent avec pertinence la participation des populations à la dynamisation de la culture et l'importance que celle-ci prend pour la communauté : importance en soi et importance pour son expression sur la scène nationale et/ou internationale, en termes tant économiques que symboliques et identitaires.

C'est ce que montre Kristina Tiedje, dans "Patrimonalisation et politisation de la cérémonie du Feu nouveau: du rituel au spectacle", à propos des Indiens nahuas et teenek de la Huastèque potosine (la Huastèque est une région s'étendant de la Sierra Madre orientale au golfe du Mexique, entre les fleuves Panuco au nord et Cazones au sud, sur trois États - Veracruz, San Luis Potosi et Hidalgo).

Le Mexique possède la "particularité" de ne pas avoir de législation de protection du patrimoine culturel des peuples autochtones, ayant tout misé sur le patrimoine matériel précolombien, privilégiant ainsi le passé au détriment du présent, glorifiant en quelque sorte un Indien "mythique". La cérémonie du Feu nouveau, qui se tient durant la semaine sainte, se déroule dorénavant sur la place centrale de la cabecera (le chef lieu) où les Indiens qui habitent les zones rurales et la montagne viennent habituellement vendre leurs produits. La cérémonie indienne consiste en un rituel de régénération et revitalisation. En 2002, avec l'accord du conseil des Anciens, elle s'est tenue pour la première fois sur la place du village métis, sous les yeux des touristes (nationaux ou étrangers), mais aussi et surtout devant les caméras de la chaîne Televisa. Après une première partie du cérémonial, le prêtre catholique et une partie des habitants se rendent en procession à l'église, pendant que la cérémonie indienne se poursuit. Entre les Indiens et le prêtre, comme entre les Indiens et la télévision, intervient un médiateur qui est là pour négocier les conditions de la réalisation du cérémonial. Ce que met en évidence Kristina Tiedje, c'est qu'une cérémonie cultuelle qui avait habituellement lieu en terre indienne s'est trouvée volontairement déplacée géographiquement par ses protagonistes afin de devenir visible par les villageois métis, par les touristes, par tout le Mexique, voire par toute l'Amérique latine via Televisa. Par ce biais, on assiste à un processus de patrimonialisation d'un culte jusqu'alors réservé, lequel participe d'une stratégie identitaire et d'une politique dans laquelle la culture (autochtone) permet de construire sa place au sein de la société mexicaine.

6 Au Costa Rica, explique Julien Laverdure ("Mucho han caminado las mascaras: l'artisanat boruca. Les entrepreneurs culturels et la construction d'un patrimoine centraméricain"), la ley indigena de 1977 stipule que les terres sur lesquelles vivent les Indiens appartiennent à l'État. Ceux-ci n'étant donc pas propriétaires, les banques refusent de leur prêter de l'argent pour investir dans la production agricole. Ils vivent donc misérablement, sauf ceux qui ont eu la bonne fortune de développer l'artisanat. Ainsi en est-il pour la population boruca (côte Pacifique) qui a pu profiter de l'intérêt que lui ont porté des intermédiaires culturels (européens ou nord-américains expatriés) ; ceux-ci, en effet, ont promu leur production artisanale (masques, tissages) sur la scène nationale, centraméricaine et mondiale. Cette promotion se combine de deux aspects : la transmission et l'amélioration des techniques de fabrication, dessins, 
ornementation des masques ou textiles d'une part, et, surtout, la fabrication par ces entrepreneurs culturels (les intermédiaires) d'un discours sur l'authenticité de la production artisanale boruca, d'autre part. Or, si celle-ci s'inscrit effectivement dans une tradition, elle est fortement empreinte du changement apporté par ces entrepreneurs culturels expatriés. Cette production, présentée comme authentique, participe au bien-être de la communauté ( $80 \%$ du village travaille dans l'artisanat, les enfants peuvent suivre des études) dont la vie quotidienne s'est améliorée, et qui en retire une visibilité et un renforcement de son identité tant sur le plan interne, au Costa Rica, qu'internationalement. Cela s'inscrit dans une stratégie culturelle qui correspond à un politique plus large des États centraméricains d'intégration dans le cadre du Sica (Système d'intégration centraméricain, fondé par le protocole de Tegucigalpa de 1991, et comprenant aujourd'hui huit États: Costa Rica, Salvador, Guatemala, Honduras, Nicaragua, Panama, Belize, République dominicaine). Cette politique vise à constituer une entité régionale intégrative, sur les plans politique, économique et culturel, afin de lutter au niveau d'une concurrence aujourd'hui globalisée. Ainsi, la promotion de la production artisanale "authentique" boruca participe, avec d'autres productions de ce type, de la stratégie globale de l'institution supranationale de créer une entité et une identité culturelle centraméricaines.

7 Mónica Martinez Mauri entraîne ensuite le lecteur au Panama, afin d'étudier les enjeux autour du trésor de Kuna Yala: tourisme, investissement étrangers et néocolonialisme au Panama ("El tesoro de Kuna Yala. Turismo, inversiones extranjeras y neocolonialismo en Panamá").

8 Pour l'auteur, il s'agit de déterminer l'impact des politiques gouvernementales de promotion du tourisme et des essais des investisseurs étrangers pour installer des entreprises touristiques à Kuna Yala, et d'analyser les rapports que les Kunas établissent avec ces mêmes étrangers. L'analyse porte sur deux moments historiques : la décennie 1970, et aujourd'hui (les années 2000).

Ce "trésor" kuna consiste en un territoire retiré des influences des ouragans et des tremblements de terre, et se compose de $200 \mathrm{~km}$ de littoral, de récifs coralliens et de 400 îles éparpillées à travers la côte atlantique : un authentique paradis paysager. Les touristes perçoivent cette terre comme vierge, sauvage et primitive. Or, ce que les touristes ne savent pas, c'est que cette terre a été transformée depuis le milieu du XIX siècle par les Kunas qui ont décidé de cultiver la noix de coco.

10 L'objet de l'article consiste à analyser le succès de la résistance des Kuna Yala aux projets touristiques et à l'internationalisation de la politique de patrimonialisation impulsée de l'extérieur, et à montrer les effets, durant les trois dernières décennies, de la politique de patrimonialisation sur le développement du tourisme ethnique entendu comme le modèle touristique qui combine la motivation pour le voyage et la découverte des choses et la connaissance des personnes. Le constat, c'est que le paysage et la culture kunas ont été patrimonialisés : dans un premier temps, par les intérêts étrangers et, dans un second temps, par les Kunas eux-mêmes afin de devenir une richesse.

11 À la suite du coup d'État du 10 octobre 1968, le gouvernement révolutionnaire instaure un certain nombre de réformes, entre autres dans le tourisme, au sein duquel se développe une technicisation par la création de l'Ipat (Instituto panameño de turismo) qui devient l'entité gestionnaire du tourisme, distribuant des subsides, établissant des statistiques, faisant la promotion, produisant des études, etc. L'Ipat définit San Blas 
(ancienne dénomination de Kuna Yala) comme un des intérêts touristiques majeurs pour la culture indigène et le paysage.

En cette époque de consolidation de l'image touristique du pays, les Kunas, leurs îles, leurs artisanats se voient patrimonialisés ; ils deviennent l'image de marque de l'Ipat et la principale attraction touristique du pays sans l'avoir demandé.

Dans les années 1970, se développent des conflits entre deux entrepreneurs hôteliers nord-américains et la chambre du conseil général kuna. Au bout d'une décennie, les deux hôtels se voient finalement détruits : l'un par le feu, l'autre par un assaut d'un groupe de jeunes Kunas.

Dans le même temps, l'Ipat promeut un projet de construction d'un complexe touristique sur la mer (évitant ainsi les îles des Kunas) afin de donner à voir la vie et la culture kunas. À travers ce projet, l'idée est bien de muséifier cette culture qui constitue un capital touristique : "La population indigène se rencontre en un surprenant état de préservation. Si des mesures de conservation et de valorisation strictes ne sont pas imposées pour éviter l'acculturation possible de l'élément indigène, et pour empêcher que ne se dissolvent leurs caractéristiques culturelles ethniques, cela conduira à la disparition non seulement de la civilisation, mais aussi de l'une des principales attractions touristiques spécifiques au pays et à la région de San Blas" (Ricardo Falla, El Tesoro de San Blas. Turismo en San Blas, Panamá, Ed. Centro de Capacitación Social, 1979).

S'ensuivirent cinq années de mésententes avec les autorités gouvernementales, les Kunas ne voulant pas d'infrastructures touristiques venant prendre les terres cultivables. Durant ces années 1970, ils luttèrent contre le gouvernement et les investisseurs étrangers avec force, ce qui ne signifie pas qu'ils étaient contre le tourisme. Au contraire, ils prirent par là même conscience du patrimoine que constituaient leur culture et le paysage, et voulurent développer par leurs propres moyens le tourisme ethnique.

Aujourd'hui, fortes du développement économique du pays, de sa stabilité politique et de l'absence de risque, les autorités de Panama veulent capter la clientèle touristique nord-américaine et européenne, pour qui le détour par Kuna Yala est "obligatoire". Cependant, à la différence des années 1970, c'est une destination promue par les Kunas eux-mêmes. En effet, en 1996, le conseil général kuna a émis une résolution réglementant l'activité touristique: seuls les Kunas peuvent établir et gérer des entreprises touristiques sur le territoire de la Kuna Yala. Après l'élection d'un nouveau président, en 2004, le nouveau ministre du Tourisme a engagé des négociations avec les Kunas afin que ceux-ci changent leur loi et permettent l'entrée d'investisseurs étrangers - l'objectif étant de pouvoir construire des hôtels de luxe dans le cadre d'un plan global de développement du tourisme à Panama, ceux-ci ne concurrençant pas la quarantaine d'hôtels des Kunas installés sur les zones frontières du territoire, afin de ne pas le dénaturer. Mais le conseil général kuna s'obstine, et refuse de changer sa loi malgré un an et demi de tractations avec l'Ipat (juillet 2005 - septembre 2006). En 2007, le conseil général kuna approuve des "normes qui régulent des activités touristiques en Kuna Yala" et crée un secrétariat au Tourisme avec l'objectif de renforcer la loi fondamentale et de réglementer les activités touristiques dirigées par les mêmes Kunas. Enfin, c'est en mars 2008 qu'est désigné, par le conseil général kuna, le premier Secrétaire au tourisme dont la mission est d'ordonner, de contrôler et de promouvoir le tourisme de la région. 
17 Martin Soares s'intéresse à la communauté tupeba de l'État du Ceará dans le Nordeste du Brésil ("Métissages et espaces transculturels : reflet d'image et mise en scène chez les Indiens Tapeba”. Cette communauté est composée de quatre ethnies qui ont été regroupées autoritairement : Potiguara, Tremembé, Kariri et Jucás. Ils reçurent un titre formel de propriété en 1723 et, en 1863, un décret déclara officiellement la disparition de toute la population indigène du Ceará. Par la perte de leur culture et de leur territoire, les groupes indigènes nordestins ont été empêchés de devenir sujet d'une action politique et ont perdu leur statut de collectivité pour devenir des groupes rémanents (remanescentes) ou descendants (descendentes). Et c'est seulement en se réunissant et en s'exposant spectaculairement qu'ils obtiennent entre eux l'unité que le terme "Indien" connote.

18 Ainsi, en 2005 est inauguré le Centro de produção cultural, maison de la mémoire tapeba, au sein de laquelle sont exposés et vendus différents produits de la culture tapeba aux touristes des plages de la région de Fortaleza. Qui plus est, ce centre culturel, sis dans la ville de Caucaiá, est constitué d'une architecture originale oca, mêlant techniques traditionnelles et contemporaines de construction, qui ne laisse pas d'éveiller la curiosité des touristes de passage sur la route nationale BR22. Les touristes sont invités à participer à la cérémonie rituelle du Toré, à entrer dans le Círculo Simbólico, et à partager le mocororó, alcool tiré du caju.

19 Aussi, par ce biais, les touristes contribuent de fait à l'“ethnicisation" des Tapeba, participant à leur construction identitaire et à leur existence sur la scène nationale brésilienne. On saisit bien ici l'enjeu politique pour ces Indiens de la promotion d'une culture qui aide aussi à cimenter la communauté.

Boullosa-Joly s'est intéressée à la fête de la Pachamama (Mère Terre), exemple de "co-constitution touristique et patrimoniale". Cette fête est devenue un enjeu majeur au sein d'un village argentin, dans un contexte de politique multi-culturaliste. Elle se déroule à l'époque du carnaval (février), dans un village de 5000 habitants, Amaicha del Valle, au nord-ouest de l'Argentine, dans la pré-cordillère des Andes. Il s'agit d'une fête très importante, car toutes les communautés des montagnes se retrouvent au village, ainsi que leurs membres qui ont émigré en ville. Elle a été instituée "fête nationale de la Pachamama" par les élites locales en 1947, à la suite de la construction de la route qui relie la vallée à Tucumán, afin de favoriser le tourisme. Il s'agit d'une tradition inventée, qui participe aujourd'hui à l'identité de la communauté. Cette fête avait été diabolisée par l'église catholique; elle est donc passée du secret à l'ostentation. C'est dans les années 1930 que la culture indienne locale est réévaluée, dans une intention touristique (la ville de Tucumán se trouve à $150 \mathrm{~km}$ ).

21 En 2001, lorsqu'une ville voisine décide de représenter la Pachamama en érigeant une statue de jeune femme enceinte à l'entrée du bourg, les villageois de Amaicha vivent cela comme un affront (car chaque année, c'est une vieille femme qui est élue Pachamama lors de leur cérémonie) et se sentent dépossédés de leur identité. Un peu auparavant, dans les années 1990, les autorités du village avaient décidé de transférer la fête de la place centrale vers le stade de football, érigeant une scène, des clôtures, faisant payer l'entrée et taxant les villageois qui construisent des stands pour vendre leurs produits. Cette initiative est alors perçue comme purement lucrative, en complète contradiction avec "l'âme Calchaqui" (les Diaguita Calchaqui étaient les habitants de la vallée au moment de la conquête hispanique). En réaction, la fondation Amauta, école culturelle mise en place par des jeunes locaux pour promouvoir l'identité culturelle de 
leur village, s'oppose aussi à la "touristification" de la fête nationale de la Pachamama, en se référant alors à la fête du $1^{\mathrm{er}}$ août, en période hivernale, pratiquée dans d'autres endroits des Andes, laquelle constitue pour eux une alternative plus authentique à la fête estivale de février. Au début des années 2000, un conseil des Anciens est créé, qui s'oppose aux malversations du cacique en place et qui, petit à petit, obtient sa légitimité auprès des médias, du secrétariat au Tourisme et de l'Inai (Institut national des affaires indiennes). Cela, à la fois pour organiser la fête nationale de la Pachamama de février, mais aussi dans la perspective de gérer des subventions de développement durable issues de la Banque mondiale pour un projet de développement des communautés indiennes.

L'auteur, à travers son enquête socio-anthropologique, montre avec clarté que cette fête, à l'origine éminemment touristique, si elle a gardé ce caractère, est toutefois devenue, au cours du temps (un demi-siècle), un élément fondamental de l'existence de la communauté villageoise de Amaicha, et un patrimoine identitaire indissociable des villageois.

L'ensemble de ces textes est très instructif en ce qui concerne la défense et l'appropriation de leur propre culture par les communautés indigènes en Amérique latine. Il met en évidence que la culture se constitue sous forme de patrimoine (par la volonté des communautés ou par des interventions exogènes) et devient un enjeu politique et un objet de stratégie pour faire perdurer ou construire une identité indienne dans des États qui possèdent, ou non, des lois de protection des cultures précédant la conquête espagnole ou portugaise. On voit que, dans ce cadre, les touristes constituent, à l'ère de la globalisation, un élément indispensable en tant que témoins, légitimant, par l'intérêt porté aux cultures autochtones l'identité de celles-ci et leur existence dans la sphère politique nationale et mondiale. 